\title{
Stone-free rate (SFR): a new proposal for defining levels of SFR
}

\author{
Bhaskar K. Somani • Mahesh Desai • \\ Olivier Traxer $\cdot$ Sven Lahme
}

Received: 14 November 2013/Accepted: 25 November 2013/Published online: 7 December 2013

(C) Springer-Verlag Berlin Heidelberg 2013

\begin{abstract}
There is a lack of consensus in the definition of stone-free rate (SFR) after ureteric or renal stone surgery. We propose a simple classification to define levels of SFR post-treatment.
\end{abstract}

Keywords Urolithiasis $\cdot$ Stones $\cdot$ Follow-up $\cdot$ Stone-free rate (SFR)

There is a lack of consensus in the definition of stone-free rate (SFR) after ureteric or renal stone surgery. We propose a simple classification to define levels of SFR posttreatment.

Based on the follow-up modality, the suffix U (USS), C (CT) or X (X-ray) should be included with the SFR level (Table 1). This simple proposal will not only clarify the

B. K. Somani $(\bowtie)$

Department of Urology, University Hospital of Southampton

NHS Foundation Trust, Southampton SO16 6YD, UK

e-mail: bhaskarsomani@yahoo.com

\section{Desai}

Muljibhai Patel Urological Hospital, Dr. Virendra Desai Road, Nadiad 387001, Gujarat, India

e-mail: mrdesai@mpuh.org

\section{O. Traxer}

Tenon University Hospital, 4 rue de la chine,

75020 Paris, France

e-mail: Olivier.traxer@tnm.aphp.fr

\section{S. Lahme}

Department of Urology, Center of minimally-invasive Therapy,

Robotic-assisted Surgery, Siloah St. Trudpert Klinikum,

Wilferdinger Strasse 67, 75179 Pforzheim, Germany

e-mail: sven.lahme@trudpert.de
Table 1 Definition of stone-free rate (SFR) level

\begin{tabular}{llll}
\hline $\begin{array}{l}\text { Stone-free rate } \\
\text { (SFR) level }\end{array}$ & $\begin{array}{l}\text { Size of stone } \\
\text { detected }\end{array}$ & $\begin{array}{l}\text { Evaluation } \\
\text { modality }\end{array}$ & SFR \\
\hline 0 & No stones & USS, CT, XR & 0U, 0C or 0X \\
1 & $\leq 1 \mathrm{~mm}$ & & $1 \mathrm{U}, 1 \mathrm{C}$ or $1 \mathrm{X}$ \\
2 & $\leq 2 \mathrm{~mm}$ & & $2 \mathrm{U}, 2 \mathrm{C}$ or $2 \mathrm{X}$ \\
3 & $\leq 3 \mathrm{~mm}$ & & $3 \mathrm{U}, 3 \mathrm{C}$ or $3 \mathrm{X}$ \\
4 & $\leq 4 \mathrm{~mm}$ & & $4 \mathrm{U}, 4 \mathrm{C}$ or $4 \mathrm{X}$ \\
\hline
\end{tabular}

size of the stone post-treatment, but also the follow-up modality used to determine it.

Conflict of interest The authors declare that they have no conflict of interest. 